\title{
Lidar returns from the upper atmosphere of Kamchatka for 2008 to 2014 observations
}

\author{
Vasily V Bychkov*, Yuri A Nepomnyashchiy, Andrey S Perezhogin and Boris M Shevtsov
}

\begin{abstract}
The correlation of lidar returns at a wavelength of $532 \mathrm{~nm}$ at altitudes of 150 to $300 \mathrm{~km}$ is investigated with the parameters of the night ionospheric F2 layer. Moreover, the role of excited ions of the nitrogen atoms in the formation of lidar signals is discussed.
\end{abstract}

\section{Findings} Introduction

In charged particle precipitations, lidar signal at a wavelength of $532 \mathrm{~nm}$ correlates with the critical frequency of the ionospheric F2 layer (Bychkov and Shevtsov 2012). This signal can be attributed to the resonant fluorescence of excited ions of atoms or molecules. In the present work, candidates for this role are considered among the components of ionospheric plasma.

Resonant fluorescence has been used in previous research to detect metal vapors at altitudes of about $100 \mathrm{~km}$. Collins et al. (2006) reported the occurrence of resonant scattering on $\mathrm{N}_{2}{ }^{+}$ions at altitudes of about $300 \mathrm{~km}$. Considering that the density of $N^{+}$exceeds that of $\mathrm{N}_{2}{ }^{+}$at altitudes of 200 to $300 \mathrm{~km}$ and that dipole $N^{+}$ transitions lie within the spectral band of the second harmonic of Nd:YAG laser radiation, the possibility exists for detection of this radiation scattering in the ionospheric F2 layer.

An analysis of lidar and radar measurements recorded in Kamchatka in 2008 to 2014 revealed a number of cases of correlation of lidar signals at a wavelength of $532 \mathrm{~nm}$ with the electron content in the ionospheric F2 layer. New observations are presented in the present study, and the possible mechanisms of lidar return signal formation in the upper atmosphere in charged particle precipitations are discussed.

\footnotetext{
* Correspondence: vasily.v.bychkov@gmail.com

Institute of Cosmophysical Research and Radio Wave Propagation of the Far Eastern Branch of the Russian Academy of Sciences, Village Paratunka, Elizovskii Region, Kamchatka Krai, Moscow 684034, Russia
}

\section{Equipment}

Data obtained with a lidar and an ionosonde in Village Paratunka, Kamchatka $\left(52.9^{\circ} \mathrm{N}, 158^{\circ} \mathrm{E}\right)$ are presented in the work. A Brilliant B Nd:YAG laser (Brilliant B, Quantel, France) with a pulse repetition frequency of $10 \mathrm{~Hz}$ was used with an energy per pulse of the second harmonic of $0.4 \mathrm{~J}$. The distance between the receiver and transmitter axes was equal to $510 \mathrm{~cm}$. The mirror of the receiving telescope had a diameter of $60 \mathrm{~cm}$ and a field of view of 0.1 to $1 \mathrm{mrad}$. To avoid intense photomultiplier tube (PMT) illumination by signals from the near field zone, the PMT was electronically locked by pulse at a duration of $140 \mu \mathrm{s}$. The signal was recorded with a step of $10 \mu \mathrm{s}$ during $4 \mathrm{~ms}$ after triggering of the laser pulse, which corresponded to a sensing range of 21 to $600 \mathrm{~km}$ with a step of $1.5 \mathrm{~km}$. The signal was accumulated for $15 \mathrm{~min}$ and was then averaged over 9,000 laser pulses. The background signal was averaged over 400 measurements from 20 to $24 \mathrm{~ms}$ after every laser pulse. A Hamamatsu H8259-01 PMT and a Hamamatsu M8784 (Hamamatsu Photonics, Hamamatsu City, Japan) photon counter were used in the receiving system. Optical filters with a passband width at the half maximum of 1 and $3 \mathrm{~nm}$ were used. The lidar and the ionosonde were synchronized using global positioning system (GPS).

The uncertainties in the measurements were estimated. The noise was the dark current of PMT plus the night sky background. The average dark current of PMT was 20/s. The counting time for the 200 to $300 \mathrm{~km}$ layer was $(2 / 3)$ ms. We recorded 9,000 laser impulses per $15 \mathrm{~min}$ and 20 $(2 / 3) 9=120$ impulses of the dark current. The night sky background was negligible in comparison with the dark current when the moon was absent and the optical filter had a passband width at the half maximum of $1 \mathrm{~nm}$. The 

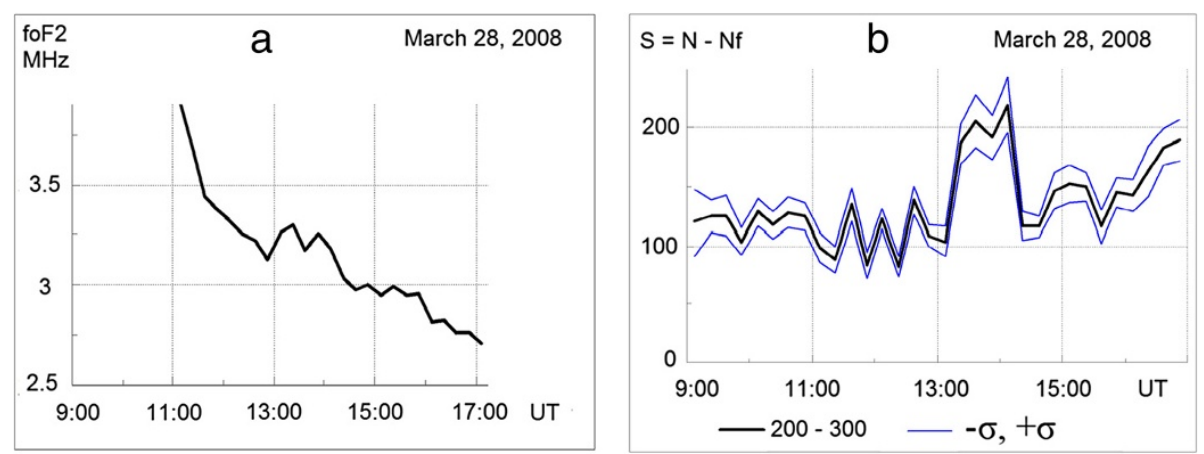

Figure 1 Critical frequency of the ionospheric F2 layer and lidar signal. (a) Critical frequency of the ionospheric F2 layer (foF2) and (b) lidar signal $S=N-N f$ summed for altitudes of 200 to $300 \mathrm{~km}$, where $N$ is the total number of detected impulses and $N f$ is the noise level. The middle curve shows the average signal, and the upper and lower curves illustrate the total standard deviations.

strong night sky background was not considered. The average lidar signal without precipitation was about 100 impulses. The dispersion was equal to the average for the Poisson process. Therefore, the relative uncertainties in the measurements, i.e., the total standard deviation of dark current and lidar signal per average lidar signal, were $(120+100)^{\wedge} 0.5 / 100=0.15$. The ratios of signal per noise were about 2 and 1 with and without precipitation, respectively.

\section{Results of 2008 observations}

Figure 1a,b shows the results obtained on 28 March 2008 (Bychkov and Shevtsov 2012).

At night from 13:00 until 14:30 UT, an increase in critical frequency was observed in the F2 layer. A rise of the same shape was simultaneously observed for the lidar signal. The geomagnetic disturbance observed after the storm with a maximum on 26 March was recorded on the same night. The local geomagnetic K-indices were equal to four during the observation period. The ionosonde registered sporadic E (Es) layers of corpuscular type at altitudes of 130 to $150 \mathrm{~km}$ with critical frequencies (foEs) of 1.5 to $1.6 \mathrm{MHz}$.
An analogous case was observed on 10 November 2008 (Bychkov et al. 2014), that included a high foEs of 4 to $5 \mathrm{MHz}$. The occurrence of the corpuscular layer specifies the precipitation of charged particles. The quiet geomagnetic conditions retained in the beginning of November were characteristic for this day. The data of Kamchatka (Paratunka) Geomagnetic Observatory indicate that the K-indices values did not exceed one on 10 November.

Figure 2a,b shows the results obtained on 6 September 2008.

The coefficient of correlation between signals from layers 200 to $300 \mathrm{~km}$ and 150 to $200 \mathrm{~km}$ was 0.83 . For altitudes above $100 \mathrm{~km}$, the correlation of signals from different layers is not typical. Analogous results were obtained on the preceding day, 5 September 2008 (Bychkov and Shevtsov 2012).

The lidar signals correlated with the F2 critical values (foF2) on 5 and 6 September 2008, after the maximum geomagnetic disturbance $(K p=6)$ on 4 September. Kamchatka ionosonde data indicate that the night Es layers were observed on 5 and 6 September at altitudes 100 to $114 \mathrm{~km}$.
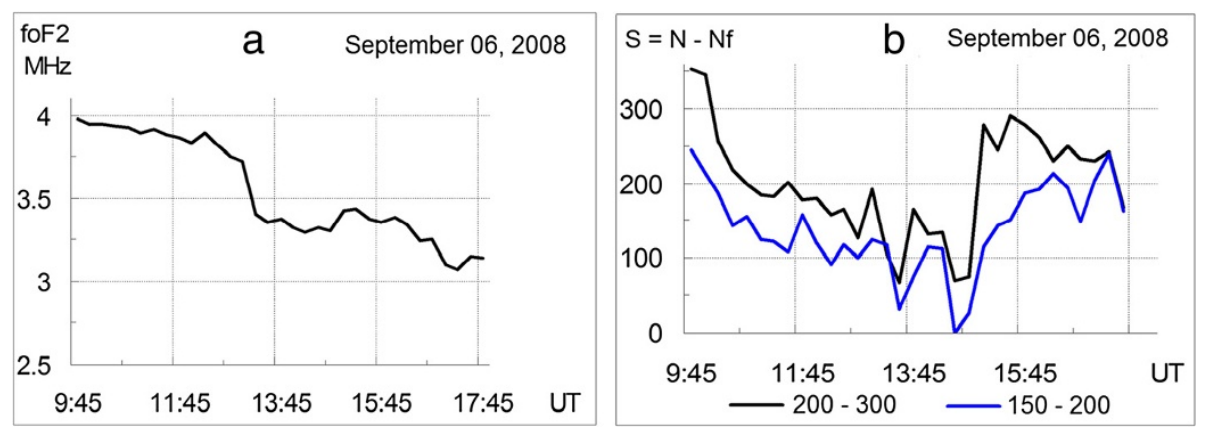

Figure 2 Critical frequency of the ionospheric F2 layer and lidar signals. (a) Critical frequency of the ionospheric F2 layer (foF2) and (b) lidar signals summed for altitudes of 150 to $200 \mathrm{~km}$ and 200 to $300 \mathrm{~km}$. 

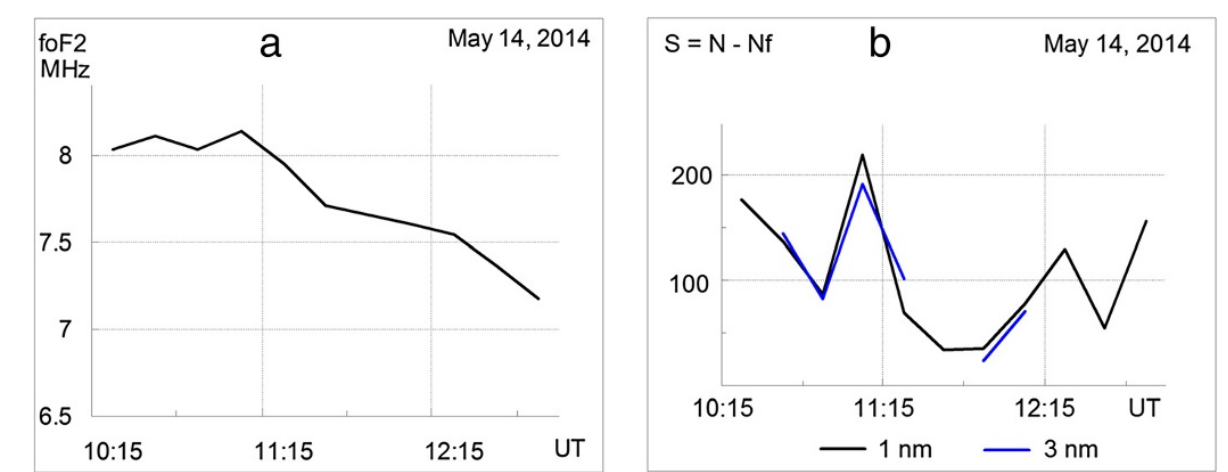

Figure 3 Critical frequency of the ionospheric F2 layer and lidar signals with the indicated degree of filtration. (a) Critical frequency of the ionospheric F2 layer (foF2) and (b) lidar signals with the indicated degree of filtration summed for altitudes of 200 to $300 \mathrm{~km}$.

\section{Observations in 2014}

In April to May 2014, lidar observations were performed with a YG-982E laser that operated at the wavelength of the second harmonic of $532 \mathrm{~nm}$ with an energy per pulse of 1.0 to $1.1 \mathrm{~J}$. The signal from the receiver was divided into two halves and was fed to two PMTs through optical filters with passbands at half maxima of 1 and $3 \mathrm{~nm}$, respectively, and identical transmittances of $T>65 \%$ to estimate the spectral width of the signal.

Figure 3a,b shows the results obtained on 14 May 2014.

On that day, Es layers were observed at 11:15, 12:30, and 12:45 UT with foEs of 2, 1.8, and $1.55 \mathrm{MHz}$, respectively. At night, all observed Es layers were corpuscular type. Maxima of lidar return signals were observed at those times (Figure 3b), as were local increases in foF2 (Figure 3a).

Good agreement of signals recorded by the receivers with narrow and wide optical filters is shown in Figure 3b, which indicates that the lidar signal frequency had not shifted and that the signal itself had a maximum spectral width of $1 \mathrm{~nm}$.

\section{Discussion of results}

A correlation of lidar return signals from altitudes of 200 to $300 \mathrm{~km}$ with the electron content of the plasma was observed during the precipitation of soft electrons in the ionosphere at hundreds of electron-volts $(\mathrm{eV})$ to kiloelectron-volts $(\mathrm{keV})$. Detection of this effect required good weather and an absence of the moon. We were able to perform observations in precipitations two to five times annually during 2008 to 2013.
The correlation of the lidar signal with the electron content of the plasma suggests that laser radiation is scattered on ions. Moreover, the unshifted signal frequency indicates the resonant character of the scattering.

The second harmonic of the Nd:YAG laser has a wavelength range $532.08 \pm 0.07 \mathrm{~nm}$, within which lie the lines of dipole transitions of ions of the nitrogen atom (NIST ASD 1978; Table 1).

The first of these lines lies in the edge of the band at $532.08 \pm 0.07 \mathrm{~nm}$, and two others fall into its center. All three transitions can apply for the role of resonant scatterer; however, the first will be excited less effectively than the third, and the density of NIII will be significantly lower than that of NII. Therefore, we considered only the third transition.

At altitudes of 200 to $300 \mathrm{~km}$, the atomic oxygen prevailed. The $\mathrm{O}^{+}$density was estimated from the electron density in the nighttime F2 layer of the ionosphere as $10^{4} \mathrm{~cm}^{-3}$. The $N^{+}$density is about $1 \%$ of the $\mathrm{O}^{+}$density (Richards 2011), which makes $10^{2} \mathrm{~cm}^{-3}$.

The excited states are characterized by the principal quantum number $n$ and the angular momentum $L$. States for which $n, L<100$ are referred to as discrete states. For larger values, the spectrum of states can be considered as continuous.

This statement follows from the estimate $2 R y / n^{3} \sim G_{1}$ $(n+1) / 2$, where $R y$ is the Rydberg constant and $G_{1}$ is the width of the first level. The left-hand side of this relationship shows the energy difference between the neighboring levels, and the right-hand side shows the total

Table 1 Lines of ions of the nitrogen atom within the band of the second harmonic of the Nd:YAG laser

\begin{tabular}{|c|c|c|c|c|c|c|c|c|c|}
\hline & & $\begin{array}{l}\text { Wavelength } \\
\text { in air }(\mathrm{nm})\end{array}$ & $\begin{array}{l}A_{k i} \\
\left(s^{-1}\right)\end{array}$ & Lower level & Term & $J$ & Upper level & Term & $J$ \\
\hline 1 & $\mathrm{NII}$ & 532.0202 & $4.20 \mathrm{e}+07$ & $2 s 2 p^{2}\left({ }^{4} P\right) 3 p$ & ${ }^{5} \mathrm{p}^{\circ}$ & 2 & $2 s 2 p^{2}\left({ }^{4} P\right) 3 d$ & ${ }^{5} \mathrm{P}$ & 1 \\
\hline 2 & NIII & 532.087 & $5.68 \mathrm{e}+07$ & $2 s 2 p\left({ }^{3} p^{0}\right) 3 p$ & ${ }^{2} \mathrm{D}$ & $5 / 2$ & $2 s 2 p\left(\left(^{3} P^{0}\right) 3 d\right.$ & ${ }^{2} F^{\circ}$ & $7 / 2$ \\
\hline 3 & $\mathrm{NII}$ & 532.0958 & $2.52 e+07$ & $2 s 2 p^{2}\left({ }^{4} P\right) 3 p$ & ${ }^{5} \mathrm{P}^{\circ}$ & 1 & $2 s 2 p^{2}\left({ }^{4} P\right) 3 d$ & ${ }^{5} \mathrm{p}$ & 2 \\
\hline
\end{tabular}


width of the level $n$. The width of the level increases with arithmetic progression such that $n$ increases and becomes comparable with the distance between the neighboring levels.

The estimate gives $n \sim 100$. Considering that $L \sim n$, the number of discrete excited states can be estimated as $n L \sim$ $(100)^{2}$. Then, the number density of the excited ions $N^{+*}$ in the state corresponding to row 3 of Table 1 can be estimated as $N^{+^{*}}=10^{-4} N^{+}=10^{-2} \mathrm{~cm}^{-3}=10^{4} \mathrm{~m}^{-3}$.

The resonant scattering cross section can be estimated as the square of the wavelength, which gives $\sigma=0.25 \times 10^{-12} \mathrm{~m}^{2}$. Then, the scattering coefficient $k=\sigma N^{+^{*}}=0.25 \times 10^{-8} \mathrm{~m}^{-1}$.

The layer with the thickness $l=100 \mathrm{~km}$ will scatter $k l=0.25 \times 10^{-3}$ photons of their total number in the laser shot. The pulse energy was approximately $0.5 \mathrm{~J}$, and the number of included photons was approximately $10^{19}$. According to the ratio of the emission line width of the ion to the width of the laser line, the fraction of resonant photons was approximately $1 / 30$. Hence, $0.25 \times 10^{16} /(4 \pi \times 30)$ photons will be scattered into the unit solid angle per pulse.

The scattering region was located approximately $250 \mathrm{~km}$ from the lidar, and the aperture area of the telescope was $0.36 \mathrm{~m}^{2}$. The solid field-of-view angle of the photon detector was approximately equal to $0.36 / 4 \pi \times$ $6.25 \times 10^{10}$. Hence, $0.25 \times 0.36 \times 10^{16} /(4 \pi)^{2} \times 187.5 \times$ $10^{10} \approx 3$ photons will arrive on the detector per laser shot.

Considering a PMT quantum efficiency of 0.1 and $9 \times$ $10^{3}$ laser pulse shots for $15 \mathrm{~min}$, we obtain $2.7 \times 10^{3}$ photon counts for $15 \mathrm{~min}$. Considering the losses in the atmosphere and in the receiving system of the lidar, the order of this value is in agreement with the 100 to 300 measured photons shown in Figures 1, 2 and 3.

In summary, we can conclude that scattering of laser radiation with a wavelength of $532 \mathrm{~nm}$ in the upper atmosphere is caused by excited nitrogen ions. As shown in Figures 1, 2 and 3, the scattering increases by a factor of 2 to 3 in soft electron precipitations.

\section{Competing interests}

The authors declare that they have no competing interests.

\section{Authors' contributions}

WB carried out the supervision and participated in the data processing. YAN was involved in optical engineering and participated in the analysis of spectral data. ASP was involved in information technology and automation of measurements. BMS carried out the supervision in laser technology and wave propagation. All authors read and approved the final manuscript.

\section{Acknowledgements}

This work was supported in part by the Project No. 12-I-OFN-16 of the Far Eastern Branch of the Russian Academy of Sciences and by the Russian Foundation for Basic Research, Grant No. 13-05-01036a.

Received: 30 March 2014 Accepted: 29 October 2014

Published online: 14 November 2014

\section{References}

Bychkov W, Shevtsov BM (2012) Dynamics of lidar reflections of the Kamchatka upper atmosphere and its connection with phenomena in the ionosphere. Geomagnetism Aeronomy 52:797-804

Bychkov W, Nepomnyashchiy YA, Perezhogin AS, Shevtsov BM, Polekh NM (2014) Lidar returns from the upper atmosphere of Kamchatka according to observations in 2008. Atmos Oceanic Opt 27:297-302

Collins RL, Su L, Lummerzheim D, Doe RA (2006) Investigating the auroral thermosphere with N2+ lidar. In: Characterising the lonosphere (PP. 2-1-2-14). Meeting Proceedings RTO-MP-IST-056, Paper 2. RTO, Neuilly-sur-Seine, France, Available at https://www.cso.nato.int/pubs/rdp.asp?RDP=RTO-MP-IST-056

NIST ASD (1978), http://physics.nist.gov/PhysRefData/ASD/lines_form.html. Online: March 1995

Richards PG (2011) Reexamination of ionospheric photochemistry. JGR:, doi:10.1029/2011JA016613

doi:10.1186/s40623-014-0150-6

Cite this article as: Bychkov et al:: Lidar returns from the upper atmosphere of Kamchatka for 2008 to 2014 observations. Earth, Planets and Space 2014 66:150.

\section{Submit your manuscript to a SpringerOpen ${ }^{\circ}$ journal and benefit from:}

- Convenient online submission

- Rigorous peer review

- Immediate publication on acceptance

- Open access: articles freely available online

- High visibility within the field

- Retaining the copyright to your article

Submit your next manuscript at $>$ springeropen.com 